\title{
Evaluation of portable ultrasound machine contamination in a community emergency department
}

\author{
Andrew Kiraly ${ }^{1}$, Adrienne Stedford ${ }^{1,2}$, Emad Awad $^{3 *}$, Gisele Adam ${ }^{1,4}$ and Floyd Besserer ${ }^{1,5,6}$ \\ ${ }^{1}$ Northern Medical Program, University of Northern British Columbia, BC Canada \\ ${ }^{2}$ Department of Family Medicine, University of Calgary, Canada \\ ${ }^{3}$ Department of Experimental Medicine, University of British Columbia, BC Canada \\ ${ }^{4}$ Department of Family Medicine, University of British Columbia, BC Canada \\ ${ }^{5} \mathrm{MD}$ Program, Faculty of Medicine, University of British Columbia, BC Canada \\ ${ }^{6}$ Department of Emergency Medicine, University of British Columbia, BC Canada
}

\begin{abstract}
Objectives: The aim of this study was to explore the gross contamination rate of a portable ultrasound (US) machine in a community Emergency Department (ED) and to examine whether there is an association between the time of the day and the frequency of contamination.

Methods: A total of 61 photographic samples of the US machine were collected over 23 days to capture visible contamination. Collection times were evenly distributed over three blocks of time: day, evening, and night. Each sample consisted of six photos of the US machine and were categorized into three groups: (1) transducers, (2) touch screen, and (3) other areas. Samples were assessed for contamination on a three-point scale by three independent reviewers. Descriptive statistics and Chi Square test were used to describe the frequency of contamination, and relationship between time of day and frequency of contamination, respectively.

Results: The transducers were contaminated with blood and body fluid in 2/62 (4\%) and ultrasound gel in 52/61 (85\%) samples. Gel contamination was found on the touchscreen in $52(85 \%)$ samples, and 42 (69\%) samples on the other areas. No significant association between time of day and contamination was found.

Conclusions: The findings of this study demonstrate various levels of gross visual contamination of the sole ultrasound machine in a community emergency department. We feel that this study provides a foundation for the development of local QI processes for US decontamination procedures as well as a platform for knowledge translation and future study.
\end{abstract}

\section{Introduction}

Over the past several decades, point of care ultrasound use in emergency departments has increased due to improved diagnostic accuracy, procedural safety, and timeliness of care [1]. With all of the benefits of emergency department ultrasound use, it is also important to understand any potential harms related to its application. Nosocomial infections are prevalent in Canadian hospitals and may be on the rise despite efforts to prevent them [2]. A robust Canada-wide study found an increase in the incidence of hospital acquired infection from 111 to 124 per 1000 patients between 2002 and 2009 despite an almost twofold increased use of isolation precautions in the same time period [2]. Nosocomial infection risk associated with emergency department (ED) visits is not well described, however, elderly patients who live in long term care facilities have been shown to have a threefold risk of acquiring an acute infection after visiting an emergency department [3]. A systematic review by Livshiz-Riven et al. [4] examined the transmission of healthcare associated infections through non-invasive portable clinical items (NPIs) shared amongst patients. The findings showed that NPIs, such as ultrasound probes, can be colonized by potentially pathogenic organisms including Staph aureus, gramnegative organisms, and multidrug resistant organisms, making them potential vectors for nosocomial infections [3,5]. In 2015, Skowronek et al. [6] looked at strains of bacteria occurring on ultrasound equipment. Pathogenic gram-negative rods were isolated from $13 \%$ of swab samples and bacteria classified as opportunistic flora, which included MRSA, were isolated from $38 \%$ of samples. A similar study by Ejtehai at al. [7] found ultrasound probe swab cultures to be positive in $98 \%$ of cases for aerobic bacteria and $52 \%$ of cases for anaerobic bacteria.

In addition to the intrinsic capacity for pathogen transfer, the risk for bacterial contamination is also increased by the presence of ultrasound gel. Several studies looking for the presence of contaminants on ultrasound equipment in hospitals have isolated bacteria that survive (and grow) in ultrasound gel as a medium [8-10]. The visible presence of gel not properly removed from ultrasound equipment has been found to correlate with bacterial contamination [11-14]. Regarding blood contamination, Keys et al. [11] found $61 \%$ of samples tested positive for blood on ultrasound equipment. Of those samples, only $51 \%$ were visibly soiled. Sanz et al. [15] found 5\% of US probes in their study had visible blood contamination. Contamination with blood is an important distinction as hepatitis $\mathrm{C}$ virus has been shown to maintain infectivity in dried blood at temperatures of $4^{\circ} \mathrm{C}$ and $22^{\circ} \mathrm{C}$ [16]. Further,

${ }^{\star}$ Correspondence to: Emad Awad, Department of Experimental Medicine, University of British Columbia, Vancouver, BC Canada, Tel: 12508080961 , E-mail: emad.awad@alumni.ubc.ca

Received: March 01, 2020; Accepted: March 21, 2020; Published: March 23 2020 
the same study found commercial antiseptic was only effective at reducing hepatitis $\mathrm{C}$ virus infectivity when used at the correct dilution [16]. Fortunately, with proper decontamination measures, colonization of bacteria on ultrasound equipment can be prevented $[12,13,15,17]$. For this reason, the literature stresses the importance of US cleaning standards and guidelines appropriate to their use, and ensuring users are well aware of these guidelines $[2,18,19]$.

The main objective of this study was to explore the gross contamination rate of a portable US machine in the ED. The secondary objective was to examine whether there was an association between the time of the day (working shift) and the frequency of the gross contamination.

The study was conducted in a 30-bed ED at a community hospital in northern BC, Canada. Data was collected by longitudinal observation over a three-week period and used to assess the efficacy of current US decontamination protocols in the ED with the intention to identify whether decontamination protocols were being followed and make recommendations for future quality improvement.

\section{Materials and methods}

To capture contamination of the ED portable US machine (GE Venue 50), standardized photographic samples were collected to capture visible gross contamination of ultrasound gel or blood and/ or body fluids (BBF). Sample were collected three times a day over 23 consecutive days. Collection times were randomly generated within, but evenly distributed to the three eight-hour blocks of time matching the standard hospital shifts of $0700-1500,1500-2300$, and 2300-0700 to allow for correlation to patterns of typical use. A fifteenminute window on either side of the sample time was allowed to accommodate unavailability of the US machine. Each sample consisted of six standardized high-resolution photos (Canon Rebel Ti) of the US machine and were categorized into three groups: (1) any of the three transducers, (2) touch screen, (3) other areas including handles, transducer cradles, cables, and the back and sides of the touch screen (Figures 1 and 2).
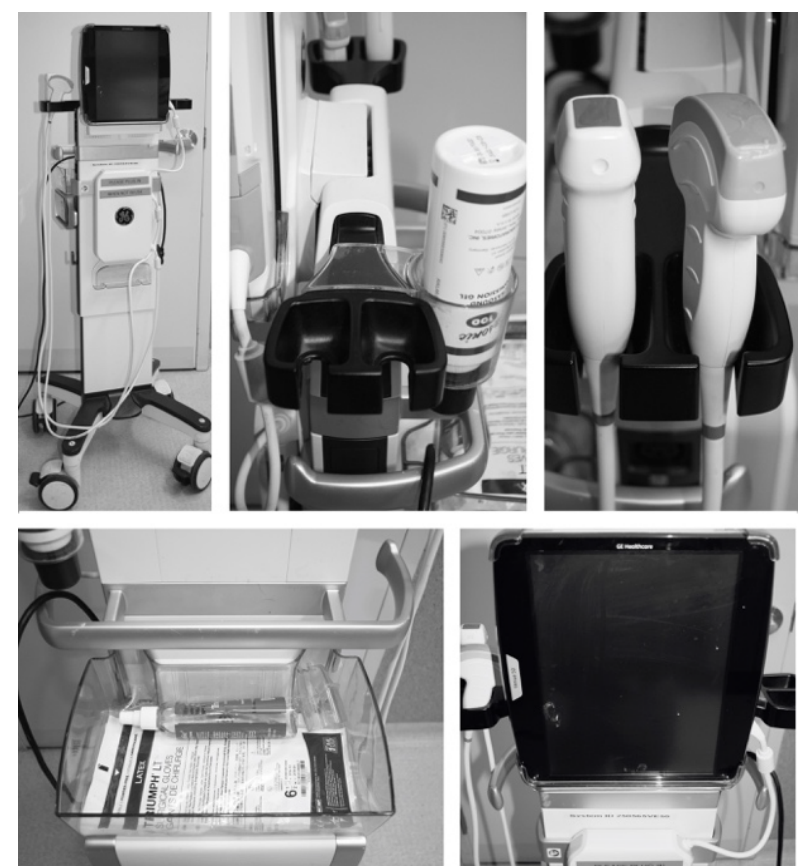

Figure 1. Standardized views of samples

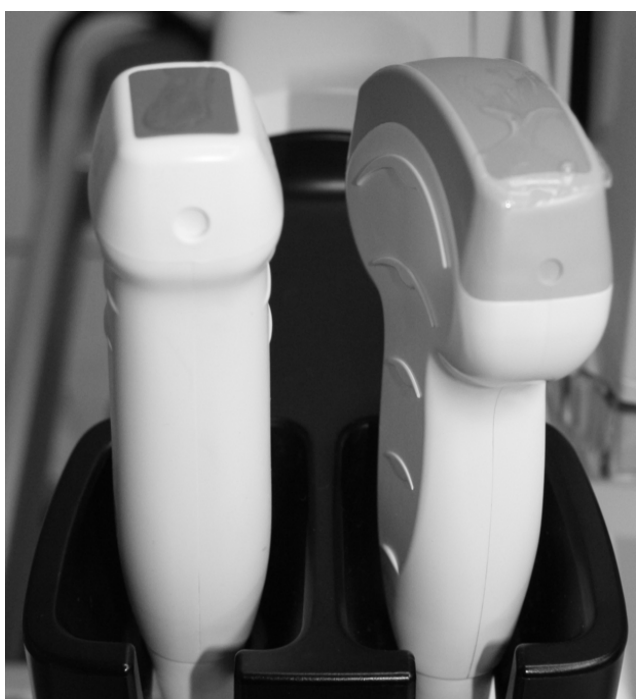

Figure 2. Example of gel contamination

Additional photos were also collected to capture detailed areas of contamination as necessary. Samples were collected by two of the authors. The study was extended by two days from 21-23 days in order to extend data collection to accommodate six missed samples (2 dayshift, 1 evening shift, 3 night shifts). The six non-collected samples were due to US equipment being used by ED staff and data collector schedule conflicts. Samples were assessed for contamination on a three-point scale (Table 1) by two independent reviewers: a registered nurse educator and an ultrasonographer. A member of the research team independent of data collection acted as a third data reviewer and tie breaker. All three data reviewer scores were equally weighted and interrater reliability was calculated. Descriptive statistics were used to describe the frequency of contamination and Chi square test was used to determine the relationship between the time of the day/working shift and the frequency of contamination. Statistical Package for Social Sciences (SPSS) version 24 was used for all statistical analyses. The UBC Behavioural Research Ethics Board was consulted and it was advised that ethics approval was not required as no human data was utilized. Operational approval was attained from the local health authority.

\section{Results}

A total of 61 samples were collected over 23 days. Contamination was observed in at least one area in all 61 samples. The transducers had the highest degree of contamination with at least one of the three transducers contaminated in $52(85 \%$; kappa $=0.804)$ samples $($ Table 2). $2(4 \%)$ of these 52 samples were contaminated with BBF, the other 50 (96\%) samples were contaminated with ultrasound gel but not BBF. The touch screen was contaminated with ultrasound gel in $52(85 \%$; $\mathrm{k}=$ 0.757) of the samples; there were no instances of BBF contamination of the touch screen. Other areas of the US machine (handles, cables, probe cradles) were contaminated with gel in $42(69 \% ; \mathrm{k}=0.656)$ of samples, with no observed BBF contamination. Although not statistically significant, the two cases of BBF contamination were both observed on during the 2300-0700 shift period.

To determine the relationship between the time of the day/working shift and the frequency of contamination, the contamination was classified into two categories: contaminated or not contaminated. Chisquare test for independence was utilized and revealed a statistically not significant association between the time of the day/shift and the frequency of presence contamination. Chi-square for the transducer 
Table 1. Contamination scale

\begin{tabular}{|l|c|}
\hline Free of any visible contamination & 0 \\
\hline $\begin{array}{l}\text { Touchscreen, or one or more probes, or other areas of the machine } \\
\text { contaminated with gel }\end{array}$ & 1 \\
\hline $\begin{array}{l}\text { Touchscreen, or one or more probes, or other areas of the machine } \\
\text { contaminated with BBF }\end{array}$ & 2 \\
\hline
\end{tabular}

Table 2. Frequency and levels of visible contamination

\begin{tabular}{|c|c|c|c|}
\hline & $\begin{array}{c}\text { Blood and Body } \\
\text { Fluid }\end{array}$ & Ultrasound Gel & No Contamination \\
\hline Transducers & 2 & 50 & 9 \\
\hline Touch Screen & 0 & 52 & 9 \\
\hline Other Areas $^{1}$ & 0 & 42 & 19 \\
\hline
\end{tabular}

${ }^{1}$ Handles, cables, probe cradles

was $\mathrm{X}^{2}(2, \mathrm{~N}=61)=3.38, \mathrm{p}=0.18$, for the touchscreen was $\mathrm{X}^{2}(2, \mathrm{~N}=$ $61)=2.0, p=0.37$, and in other sites of the US machine was $X^{2}(2, N=$ $61)=1.0, \mathrm{p}=0.60$

\section{Discussion}

Emergency departments can be fast-paced and chaotic clinical environments that may influence the ability to standardize cleaning protocols and procedures. Chemical disinfectants have recommendations for specific usage and contact time required in order to be effective [19]. This poses a challenge regarding effective disinfection practice in emergency situations requiring time-sensitive use of a portable US machine that requires disinfection. In addition to minimizing the risk of infection transmission to both patient and operator, the manufacturer protocol for the GE Venue 50 recommends cleaning and disinfection practices to ensure the ultrasound machine operates at maximum efficiency [20]. Effective strategies for improving contamination rates of portable ultrasound machines will likely be specific to each emergency department, taking into consideration factors such as overall patient volume, patient flow throughout various shifts, staffing, and even the layout of the department.

Within the study, transducers were observed to have the highest level of contamination, both in number of times contaminated (52/61 samples), and with degree of contamination (2/61 BBF contamination). Although microbial analysis was inferred by the presence of gross contamination, prior research has established that ultrasound gel is a conducive medium for pathogen growth and preservation. [2-4] While any area of contamination poses a risk, the transducers are in direct contact with the patient and may pose the highest risk for pathogen transmission. There was a high degree of interrater correlation for contamination of the transducers $(\mathrm{k}=0.804)$. Interrater correlation was also strong for the touch screen, however the other area of examination had marginal interrater correlation $(\mathrm{k}=0.656)$, which is consistent with the difficulty to clearly capture and identify contamination at these sites.

\section{Limitations}

There were several limitations to the study design. The samples collected represent a moment in time, and do not reflect cleaning that may have occurred prior to use of the machine. The assumption was made that the 23-day period of data collection was representative of typical use. There are many factors that influence ultrasound machine use and cleaning that may not have been captured in this study: volume of ED patient load and acuity, staff predilection for using the US machine, and the experience and prior training/orientation of staff including physicians, nurses, and ancillary staff. A future study looking at specific variables could provide clarity in factors contributing to contamination. Another limitation was the potential for bias by having multiple data collectors taking the photos that would ultimately be evaluated to produce the results. This was mitigated by having a standardized process of data collection with a routine set of photos taken for each sample. However, to capture subtle areas of contamination, the data collectors had to take additional photos at their discretion to capture contamination. The image quality and discretion of data collectors had potential to influence the samples that the data evaluators received, which is a potential cause of the marginal interrater correlation $(\mathrm{k}=0.656)$ for areas other than the transducers $(0.804)$ and touch screen $(\mathrm{k}=0.757)$. In future evaluation, it may be advantageous to have the data collector highlight areas of contamination for clarity in the review and grading stage.

\section{Conclusion}

The findings of this study demonstrate various levels of gross visible contamination of the sole ultrasound machine in a community emergency department. Future evaluation is warranted following knowledge translation to identify the underlying factors contributing to reduced utilization of ultrasound decontamination procedures. Ultimately, this can inform quality improvement initiatives to reduce the risk of disease transmission from contaminated ultrasound equipment.

\section{References}

1. (2017) Ultrasound Guidelines: Emergency, Point-of-Care and Clinical Ultrasound Guidelines in Medicine. Ann Emerg Med 69: e27-27e54. [Crossref]

2. Taylor G, Gravel D, Matlow A, Embree J, LeSaux, et al. (2016) Assessing the magnitude and trends in hospital acquired infections in Canadian hospitals through sequential point prevalence surveys. Antimicrob Resist Infect Control 5: 19-7. [Crossref]

3. Quach C, McArthur M, McGeer A, Li L, Simor A, et al. (2012) Risk of infection following a visit to the emergency department: A cohort study. CMAJ 184: E232. [Crossref]

4. Livshiz-Riven I, Borer A, Nativ R, Eskira S, Larson E (2015) Relationship between shared patient care items and healthcare-associated infections: A systematic review. Int J Nurs Stud 52: 380-392. [Crossref]

5. Schabrun S, Chipchase L (2006) Healthcare equipment as a source of nosocomial infection: A systematic review. J Hosp Infect 63: 239-45. [Crossref]

6. Skowronek P, Wojciechowski A, Leszczynski P, Olszewski P, Sibinski M, et al. (2016) Can diagnostic ultrasound scanners be a potential vector of opportunistic bacterial infection? Med Ultrason 18: 326. [Crossref]

7. Ejtehadi F, Teb JC, Arasteh MM (2015) A safe and practical decontamination method to reduce the risk of bacterial colonization of ultrasound transducers: Bacterial colonization of US probes. J Clin Ultrasound 42: 395-398. [Crossref]

8. Weist K, Wendt C, Petersen LR, Versmold H, Rüden H (2000) An outbreak of pyodermas among neonates caused by ultrasound gel contaminated with methicillinsusceptible staphylococcus aureus. Infect Control Hosp Epidemiol 21: 761-764. [Crossref]

9. Muradali D, Gold W, Phillips A, Wilson S. Can ultrasound probes and coupling gel be a source of nosocomial infection in patients undergoing sonography? an in vivo and in vitro study. AJR Am J Roentgenol. 1995 Jun; 164(6): 1521. [Crossref]

10. Spencer P, Spencer RC (1988) Ultrasound scanning of post-operative wounds--the risks of cross-infection. Clin Radiol 39: 245-246. [Crossref]

11. Keys M, Sim BZ, Thom O, Tunbridge MJ, Barnett AG, et al. (2015) Efforts to Attenuate the Spread of Infection (EASI): a prospective, observational multicentre survey of ultrasound equipment in Australian emergency departments and intensive care units. Crit Care Resusc 17: 43-46. [Crossref]

12. Chu K1, Obaid H, Babyn P, Blondeau J (2014) Bacterial contamination of ultrasound probes at a tertiary referral university medical center. AJR Am J Roentgenol 203: 928932. [Crossref] 
13. Mullaney PJ, Munthali P, Vlachou P, Jenkins D, Rathod A, et al. (2007) How clean is your probe? microbiological assessment of ultrasound transducers in routine clinical use, and cost-effective ways to reduce contamination. Clin Radiol 62: 694-98. [Crossref]

14. Bello TO, Taiwo SS, Oparinde DP, Hassan WO, Amure JO (2005) Risk of nosocomial bacteria transmission: Evaluation of cleaning methods of probes used for routine ultrasonography. West Afr J Med 24: 167. [Crossref]

15. Sanz GE, Theoret J, Liao MM, Erickson C, Kendall JL (2011) Bacterial contamination and cleanliness of emergency department ultrasound probes. Can J Emerg Med 13: 384-389. [Crossref]

16. Paintsil E, Binka M, Patel A, Lindenbach BD, Heimer R (2014) Hepatitis C virus maintains infectivity for weeks after drying on inanimate surfaces at room temperature: implications for risks of transmission. J Infect Dis 209: 1205-1211. [Crossref]
17. Kibria SMG, Kerr KG, Dave J, Gough MJ, Homer-Vanniasinkam S, et al. (2002) Bacterial colonisation of doppler probes on vascular surgical wards. Eur $J$ Vasc Endovasc Surg 23: 241-243. [Crossref]

18. Moshkanbaryans L, Meyers, C, Ngu A, Burdach J (2015) The importance of infection prevention and control in medical ultrasound. Australas J Ultrasound Med 18: 96-99. [Crossref]

19. Ontario, Ontario PH (2013) Canadian Electronic Library (Firm), Scholars Porta Books: Legislative Library of Ontario. Best Practices for Cleaning, Disinfection and Sterilization of Medical equipment/devices in all Health Care Settings. ( $3^{\text {rd }}$ Edn). Public Health Ontario.

20. (2013) General Electric Co. Venue 50 basic user manual. GE Technical Publications.

Copyright: @2020 Kiraly A. This is an open-access article distributed under the terms of the Creative Commons Attribution License, which permits unrestricted use, distribution, and reproduction in any medium, provided the original author and source are credited. 